Special Issue of the 8th International Advances in Applied Physics and Materials Science Congress (APMAS 2018)

\title{
Linear Low Density Polyethylene Filled with Almond Shells Particles: Mechanical and Thermal Properties
}

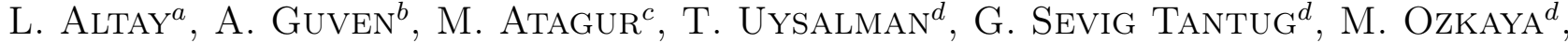 \\ K. SEVER ${ }^{c}$, M. SARIKANAT ${ }^{a, *}$ AND Y. SEKI ${ }^{e}$ \\ ${ }^{a}$ Ege University, Mechanical Engineering Department, Bornova, Izmir, Turkey. \\ ${ }^{b}$ Ankara Ylldırım Beyazit University, Mechanical Engineering Department, Keçiören, Ankara, Turkey \\ ${ }^{c}$ İzmir Katip Celebi University, Faculty of Engineering and Architecture, Çiğli, Izmir, Turkey

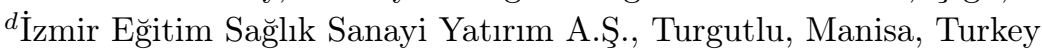 \\ ${ }^{e}$ Dokuz Eylul University, Faculty of Science, Buca, Izmir, Turkey
}

\begin{abstract}
The aim of this study is to investigate mechanical and thermal properties of linear low density polyethylene (LLDPE)-based composite prepared with different almond shells powder (AS) contents. In this paper, AS (5, 10, 20, 30, and $40 \mathrm{wt} \%$ ) filled LLDPE composites were prepared by compounding polyethylene and AS using a corotating twin screw extruder. All specimens for mechanical tests were molded using injection molding. $40 \mathrm{wt} \% \mathrm{AS}$ filling into LLDPE has led to $100 \%$ increase in flexural strength of LLDPE. AS filling into LLDPE decreased the MFI value of LLDPE. AS filling into LLDPE at low weight fractions (5 and 10\%) has not affected the un-notched impact strength of LLDPE. Thermal properties of the composite were studied by thermal gravimetric analysis (TGA). From TGA analysis, it is seen that degradation of AS within LLDPE started at about $200^{\circ} \mathrm{C}$
\end{abstract}

DOI: 10.12693/APhysPolA.135.1042

PACS/topics: almond shells, polyethylene, mechanical properties, composite materials

\section{Introduction}

Disposing of agro-waste in ways other than incineration or landfilling has recently drawn attention. Agrowaste materials are often introduced in polymers to improve mechanical and structural performance as well as cost reduction [1]. Therefore alternative with cheap sustainable and easily available agro-waste materials which also lead to considerable increase in performance of polymers are demanded. The Almond Shell (Prunus Dulcis) is one of the most abundant and low-cost product which is available as a waste compound [2]. The almond shell has no important industrial value and it is normally incinerated or dumped [3-4]. It was reported that almond shell flour could play an important role in the fabrication of filled thermoplastic composites and wood-based panels, thus reducing the requirement for wood material $[3,5]$. However, attempts to re-use almond shell wastes as a filler material for polymer have been limited so far.

With respect to 2013 data, Turkey, which produced 69838 tons almond in a year, was ranked seventh in the world [6]. In recent years, production of almonds has increased significant in Turkey because of improvement of agricultural techniques and growing number of almond cultivars [6-7]. It is clear that large amount of almond shell (AS) wastes are produced in Turkey. The aim of this study is to examine the effect of Almond Shell waste on

*corresponding author; e-mail: sarikanat.mehmet@gmail.com mechanical and thermal properties of linear low density polyethylene (LLDPE). Besides it was also reported that almond shells consist of a $37 \mathrm{wt} \%$ of cellulose, $32 \mathrm{wt} \%$ hemicelluloses, $27 \mathrm{wt} \%$ of lignin and $4 \mathrm{wt} \%$ of other components $[1,8]$. It is expected that its relatively high lignin content may improve the polymer performance in a positive sense.

\section{Experimental and fabricating method}

Linear low-density polyethylene (LLDPE) resin having a density of $0.92 \mathrm{~g} / \mathrm{cm}^{3}$ and melt flow rate of $14.7 \mathrm{~g} / 10$ min used in this study was supplied by Hanwa. Besides, AS was ground and sieved into a size smaller than $50 \mu \mathrm{m}$. Maleic Anhydride Grafted Polypropylene (MAPP) purchased from Lushan (PR-3C) as granules was used as a compatibilizer to fabricate AS filled LLDPE with 5wt\% of MAPP composites. AS filled LLDPE composites with 5, 10, 20, 30 and $40 \mathrm{wt} \%$ of AS flour (LLDPE-5AS, LLDPE-10AS, LLDPE-20AS, LLDPE-30AS and LLDPE-40AS) were manufactured by using a co-rotating twin screw extruder (Leistritz Model ZSE 27 Extruder, Germany) with 300 rpm at barrel temperatures of $150-180^{\circ} \mathrm{C}$. Test specimens were manufactured from AS filled LLDP composite granules using injection molding machine (Bole, model BL90EK, China). Density measurement of the specimens was done according to the ASTM D792 using densimeter MD-200S. The density of each composite was obtained by calculating the average of the density of specimens. Melt flow index for composite granules was measured by using Göttfert melt indexer mi2.2 according to ASTM D-1238 standard. The melt temperature was $230^{\circ} \mathrm{C}$ and piston load 
was $2.16 \mathrm{~kg}$. The three point bending tests of LLDPE and AS filled LLDPE composites were carried out at room temperature using a Hegewald\&Peschke inspekt table blue Series universal testing machine at a crosshead speed of $2 \mathrm{~mm} / \mathrm{min}$ according to the ASTM D-790 standards. Flexural strength and modulus were reported for each specimen. The un-notched Izod impact strength was measured with a pendulum-type tester (Keijan, China) at $23^{\circ} \mathrm{C}$ with $5 \mathrm{~J}$ stricker according to ASTM D256. At least three tests were performed for each sample. TGA Analysis of LLDPE and AS filled LLDPE composites were conducted by using TG Analyzer (TA Instrument, Q 50). Analysis was made from room temperature to $800^{\circ} \mathrm{C}$ with a heating rate of $10^{\circ} \mathrm{C} / \mathrm{min}$ under nitrogen atmosphere.

\section{Results and discussions}

\subsection{Density}

Figure 1a shows the density values of LLDPE and its composites. As it is seen from Fig. 1a, density values of composites are higher than LLDPE itself. The density of the composites increased (from 0 to $40 \mathrm{wt} \%$ ) linearly with an increase in weight percentage of filler [9].

\subsection{Melt flow index}

MFI values of LLDPE and its composites are given in Fig. 1b. As it is expected, MFI value of composites decreased with increasing AS filler concentration. There is no sharp decrease in $5 \%$ wt and $10 \%$ wt AS filling into LLDPE. However, a sharp decrease in MFI value was observed after $20 \mathrm{wt} \%$ AS filling into LLDPE. MFI value decreased $63 \%$ when $40 \mathrm{wt} \%$ AS was filled into LLDPE.

\subsection{Mechanical properties}

Flexural strength and modulus of LLDPE and its composites are shown in Table I. Flexural strength of LLDPE was increased with the addition of AS into LLDPE. Incorporation of 5 and $10 \mathrm{wt} \%$ AS led to $55 \%$ increase in comparison with LLDPE itself. While LLDPE matrix has $6 \mathrm{MPa}$ flexural strength, LLDPE-20AS, LLDPE$30 \mathrm{AS}$, LLDPE-40AS have flexural strength values of $10.67,12.05$, and 13.24 MPa, respectively. When $40 \mathrm{wt} \%$ AS filled composite was investigated, $100 \%$ increase in flexural strength was obtained. Incorporation of AS particles into LLDPE significantly increased its flexural modulus, which is caused by the reinforcement effect of AS. Therefore, the rigidity of the material increased with the addition of the filler [5]. As it can be seen from Table I, the highest flexural modulus was obtained when $40 \mathrm{wt} \%$ AS was used in the composites.

Un-notched Izod impact strength values of LLDPE and its composites are given in Table I. AS fillings into LLDPE by weight fractions of 5 and $10 \mathrm{wt} \%$ have no negative effect on un-notched Izod impact strength of LLDPE. However, 20, 30, and $40 \mathrm{wt} \%$ AS fillings into LLDPE affected impact strength inversely. Therefore,
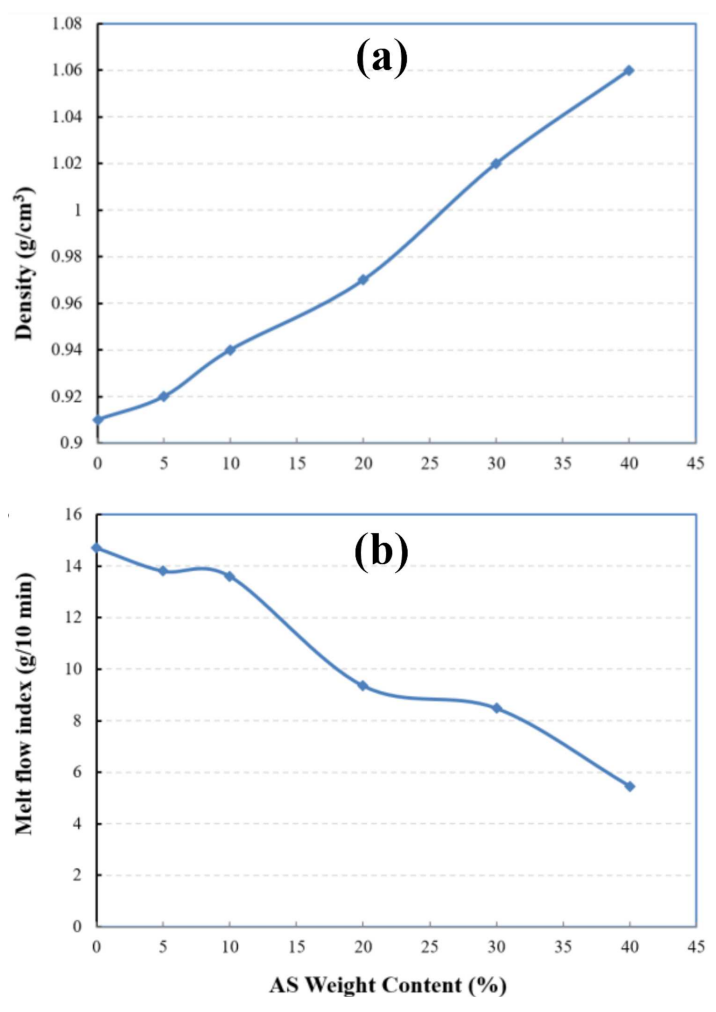

Fig. 1. Density (a) and melt flow index (b) values of LLDPE and its composites.

TABLE I

Mechanical Properties of LLDPE and AS filled LLDPE composites.

\begin{tabular}{c|c|c|c}
\hline \hline Sample & $\begin{array}{c}\text { Flexural } \\
\text { strength } \\
{[\mathrm{MPa}]}\end{array}$ & $\begin{array}{c}\text { Flexural } \\
\text { modulus } \\
{[\mathrm{MPa}]}\end{array}$ & $\begin{array}{c}\text { Un-notched Izod } \\
\text { impact strength } \\
{\left[\mathrm{kJ} / \mathrm{m}^{2}\right]}\end{array}$ \\
\hline LLDPE & $6.00 \pm 0.04$ & $37 \pm 5$ & $\mathrm{NB}$ \\
LLDPE-5AS & $9.31 \pm 0.12$ & $182 \pm 21$ & $\mathrm{NB}$ \\
LLDPE-10AS & $9.32 \pm 0.11$ & $219 \pm 54$ & $\mathrm{NB}$ \\
LLDPE-20AS & $10.67 \pm 0.23$ & $234 \pm 10$ & $21.71 \pm 1.25$ \\
LLDPE-30AS & $12.05 \pm 0.17$ & $246 \pm 54$ & $16.99 \pm 0.98$ \\
LLDPE-40AS & $13.24 \pm 0.23$ & $314 \pm 48$ & $11.60 \pm 0.89$
\end{tabular}

impact strength of LLDPE decreased with the increasing AS filling from 20 to $40 \mathrm{wt} \%$. Poor interfacial interaction induces micro-voids between the filler and matrix polymer, and those cause numerous micro-cracks when impact occurs, which induce crack propagation easily and decrease the impact strength of the composites [10].

\subsection{TGA analysis}

TGA curves of LLDPE and AS filled LLDPE composites can be seen in Fig. 2. Maximum degradation temperatures of LLDPE, LLDPE-5AS, LLDPE-10AS, LLDPE20AS, LLDPE-30AS, and LLDPE-40AS were obtained to be $474,456,464,472,476$, and $472^{\circ} \mathrm{C}$, respectively. It is seen that AS addition into LLDPE has not affected the 
maximum degradation of LLDPE. When low amounts of AS, 5 and $10 \mathrm{wt} \%$, were added into LLDPE, mass loss due to AS degradation is not visible from TGA curves of composites. However, when AS was added at the weight fractions $20 \mathrm{wt} \%$ and beyond, mass losses becuase of degradation of almond shell are remarkable. Besides degradation of AS within LLDPE started at about $200^{\circ} \mathrm{C}$.

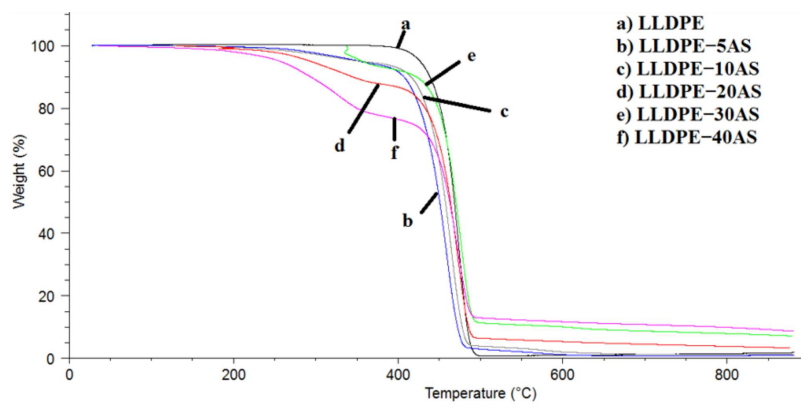

Fig. 2. TGA curves for LLDPE and AS filled LLDPE composites.

\section{Conclusion}

AS filled LLDPE composites were produced by using twin screw extruder. The main conclusions drawn from this study are as follows:

- Melt flow index of the composites decreases as weight fraction of AS increases from 5 to $40 \%$;

- The density of composites increases with increasing AS weight fraction;

- Improvement in flexural strength with weight fraction up to $40 \%$ is observed. Flexural modulus of composites increases with the addition of AS into LLDPE.
- 5 and 10 wt\% AS fillings into LLDPE have no negative effect on un-notched Izod impact strength of LLDPE. Un-notched Izod impact strength of LLDPE decreases with the increasing AS filling from 20 to $40 \mathrm{wt} \%$.

- AS addition into LLDPE has not affected the maximum degradation temperature of LLDPE. Degradation of AS within LLDPE starts at about $200^{\circ} \mathrm{C}$.

\section{References}

[1] A. Sabbatini, S. Lanari, C. Santulli, C. Pettinari, $M a-$ terials 10, 872 (2017).

[2] M. Jabli, E. Gamha, N. Sebeia, M. Hamdaoui, J. Mol. Liq. 240, 35 (2017).

[3] S.K. Hosseinihashemi, A. Eshghi, N. Ayrilmis, H. Khademieslam, Bioresources 11, 6768 (2016).

[4] A. Lashgari, A. Eshghi, M. Farsi, Asian J. Chem. 25, 1043 (2013)

[5] A. Valdés García, M. Ramos Santonja, A. Beltrán Sanahuja, M. del Carmen Garrigós Selva, Polym. Degrad. Stab. 108, 269 (2014).

[6] N. Mustafa Nizamlıoglu, S. Naz, Int. J. Sec. Metabolite 4, 134 (2017).

[7] S. Sathe, E. Monaghan, H. Kshirsagar, M. Venkatachalam, in: Tree Nuts Composition, Phytochemicals, and Health Effects, Eds. C. Alasalvar, F. Shahidi, CRC Press, Boca Raton 2008, p. 11.

[8] J.A. Caballero, J.A. Conesa, R. Font, A. Marcilla, J. Anal. Appl. Pyrol. 42, 159 (1997).

[9] M. Tasdemir, IOP Conf. Series: Materials Science and Engineering 204, 012015 (2017).

[10] H.S. Yang, H.J. Kim, J.G. Son, H.J. Park, B.J. Lee, T.S. Hwang, Compos. Struct. 63 (2004). 